\title{
Políticas penais no Paraná - do avanço do aprisionamento ao gerenciamento da massa de apenados
}

\section{Penal policies in the state of Paraná - progress in imprisonment to the management of the jailed community}

\author{
Rivail Carvalho Rolim* \\ Letícia Gonçalves Martin**
}

\begin{abstract}
Resumo
Nas últimas décadas, houve um aumento significativo do aprisionamento no país, resultado das políticas penais que procuram tratar qualquer tipo de conflito social com políticas repressivas e penais. Este trabalho procura analisar as políticas de segurança pública adotadas no Paraná para enfrentar os problemas sociais no estado, bem como desnudar a seletividade constante na intervenção do aparato repressivo-judicial no aprisionamento das pessoas e no gerenciamento dos apenados.
\end{abstract}

Palavras chave: segurança pública; polícia; políticas penais; prisões.

\begin{abstract}
A significant increase in jailed people has been reported in the last few decades, due to penal policies which endeavor to solve any type of social conflict by resorting to repressive and penal policy. Public security policies to cope with the social problems in the state of Paraná, Brazil, are analyzed. Furthermore, the constant selection in the intervention of the repressivejudicial apparatus for the internment of suspects and the managements of jailed people is revealed.
\end{abstract}

Keywords: public safety; police; penal policies; prisons.

\footnotetext{
* Doutor em História pela Universidade Federal Fluminense. Professor do Departamento do Programa de Pós-Graduação (Mestrado/Doutorado) em História e do Programa de Mestrado em Políticas Públicas da Universidade Estadual de Maringá. E-mail: rivailrolim@hotmail.com

${ }^{*}$ Mestre pelo Programa de Mestrado Profissional em Políticas Públicas da Universidade Estadual de Maringá e Assistente Social do Departamento Penitenciário do Estado do Paraná.
} 
Nos últimos anos, embora tenham aumentado significativamente os trabalhos sobre as políticas penais e o sistema prisional no país, ainda são poucas as pesquisas referentes ao tema no Paraná. Entendemos, portanto, que um estudo que aprofunde tais reflexões pode contribuir para avançarmos em sua compreensão nos últimos anos. Nesse sentido, neste artigo procuramos aprofundar as pesquisas relativas ao sistema prisional e às políticas penais presentes no Brasil, com uma reflexão acerca desse tema no estado paranaense.

No encaminhamento do trabalho, não perdemos de vista que as políticas penais devem ser entendidas em uma perspectiva mais ampla, haja vista que, nesse mundo globalizado, experiências sociais que vêm ocorrendo nas nações mais industrializadas acabam servindo como paradigma em nosso país. O pressuposto, por exemplo, nos principais países ocidentais de que problemas sociais devem ser resolvidos com mais políticas penais ganhou proeminência e forjou uma capacidade de difusão social que permitiu a constituição de universos compartilhados de identificação social que vão além da experiência social originária.

Nesta reflexão, primeiramente fazemos uma incursão sobre as políticas penais contemporâneas oriundas dos países centrais do capitalismo e sobre como elas passaram a influenciar o debate atinente à segurança pública na sociedade brasileira a partir da década de 1990. Em um segundo momento, voltamos nossas atenções para as políticas penais no Paraná, não perdendo de vista que aquilo que está sendo levado a cabo pelo estado recebe os influxos das políticas penais e de segurança pública em curso no país e até mesmo do exterior.

\section{0 avanço do estado penal na atualidade e suas implicações nas políticas repressivas na sociedade brasileira nas últimas décadas}

Para iniciarmos a análise, temos de salientar que a lógica do estado penal estadunidense, que ganhou vários adeptos na Europa, chegou também ao Brasil nas últimas décadas. Exportado como um importante componente da cultura repressiva dos Estados Unidos, foi recepcionado em nosso país com grande entusiasmo justamente quando se iniciava uma nova experiência democrática, depois de anos de ditadura militar.

Embora o ideário do estado penal estadunidense tenha sido incorporado como um paradigma pelos países europeus e também pela sociedade brasileira para lidar com uma realidade perpassada por conflitos sociais, os desdobramentos foram bastante diferenciados nos dois espaços. Na Europa, foi utilizado justamente para lidar com os efeitos do desmonte do estado de 
bem-estar social construído após a Segunda Guerra Mundial; já no Brasil foi utilizado para fazer frente aos grandes problemas sociais ou mesmo para frear iniciativas que visavam estruturar políticas públicas com vistas a atender segmentos sociais marcados por um alto nível de vulnerabilidade social.

No que diz respeito ao controle social punitivo adotado como política nos países centrais do capitalismo, vale ressaltar que no Brasil tais práticas remontam não apenas à incorporação do estado penal estadunidense ou mesmo à herança da ditadura militar, mas a uma sociedade que possui uma trajetória histórica caracterizada pela premissa de reprimir qualquer conflito social ou político. Este ideário de que os problemas sociais devem ser tratados com a repressão legal e até mesmo ilegal insiste em permanecer como estratégia de ação do aparato repressivo-judicial na atualidade.

$\mathrm{Na}$ realidade, com o fim da ditadura militar, as esperanças eram no sentido de que havia chegado o momento de construirmos uma sociedade livre, justa e solidária, erradicar a pobreza e a marginalização e reduzir as desigualdades sociais e regionais, de acordo com o que estabelecia a Constituição de 1988, mesmo porque a sociedade brasileira tinha muitos problemas a resolver dado o déficit social acumulado em nossa trajetória histórica. Bastante sintomático para chegarmos a essa conclusão é o fato de no início da década de 1980 o Brasil ser considerado o país mais desigual do mundo.

Todavia, quando começávamos a trilhar um novo caminho, que se propunha a ser diferente dos períodos históricos anteriores, pois tínhamos colocado, inclusive, na denominada constituição cidadã um capítulo tratando especificamente dos direitos sociais, passou a ganhar muita força no território brasileiro o ideário neoliberal, que já estava em marcha acelerada nos países centrais do capitalismo e em alguns da América Latina. Assim, alguns agentes políticos que rapidamente se apropriaram dessas ideias políticas começaram a classificar a Constituição de 1988 de perdulária e populista e passaram a criar inúmeros obstáculos para que laivos de um constitucionalismo social, embora muito distantes do welfare state, fossem implantados no país. ${ }^{1}$

Diante de um déficit social enorme, que gestava um cenário conflituoso no país, iniciou-se um processo no sentido de impor como a realidade brasileira deveria ser nomeada e classificada com a finalidade de serem definidas quais estratégias deveriam ser adotadas para fazer frente aos grandes problemas sociais. Nas palavras de Bourdieu, “ao se estruturar a percepção que os agentes sociais devem ter do mundo social, a nomeação contribui para constituir a

${ }^{1}$ ROLIM, Rivail Carvalho. Políticas penais e os dilemas da construção de um estado de direito no Brasil. Revista Fênix, v. 9, ano IX, n. 1, 2012 
estrutura desse mundo". ${ }^{2}$ Nesse caso, podemos citar o efeito da teoria, isto é, o avanço das ideias neoliberais contribuiu para impor uma maneira mais ou menos autorizada de ver o mundo social.

Desse modo, se estávamos diante de um cenário promissor para os avanços de uma democracia social no país com a promulgação da denominada constituição cidadã, na qual o pressuposto era de que o poder público, por intermédio de suas agências, implantaria políticas públicas para erradicar a imensa pobreza, o analfabetismo, a marginalização e as desigualdades para justamente diminuir os grandes conflitos sociais, o caminho seguido foi bastante distinto daquele que muitos agentes que participaram intensamente do processo constituinte tinham propugnado.

A maneira de ver o mundo foi no sentido de definir que o cenário social do país estava permeado por intensos conflitos sociais provocados por uma série de comportamentos qualificados como de atos ilícitos cometidos por aqueles que moravam em bairros periféricos e favelas, os quais acarretavam grandes problemas de segurança pública. Portanto, a forma autorizada de ver o mundo social foi de que estávamos diante de um aumento vertiginoso da criminalidade, que veio, logicamente, acompanhada de um alto grau de alarme social, alimentado, em grande parte, pelos meios de comunicação. ${ }^{3}$

Os imensos problemas sociais presentes no país foram compreendidos como um grande problema de segurança pública e não de políticas públicas de segurança, e a opção foi tratá-los via aparato repressivo-judicial e sempre optar pela repressão para resolvê-los. O resultado, para usarmos as palavras de Loic Wacquant, foi de se criar uma verdadeira ditadura sobre os pobres. ${ }^{4}$ Devido a isso que o sociólogo francês, grande estudioso das políticas penais na contemporaneidade, assevera que apesar da ditadura militar no Brasil ter acabado no plano político, o autoritarismo ainda prevalece e pode ser percebido nas ações repressivas da polícia em bairros marginalizados.

As práticas do aparato repressivo foram norteadas, em grande medida, pela política de "tolerância zero" gestada em território estadunidense. Aliás, para muitos políticos e apresentadores de programas televisivos e radiofônicos apareceu como o canto da sereia. Tal como nos Estados Unidos e Europa, no Brasil também nos deparamos com uma mídia que passou a construir

\footnotetext{
${ }^{2}$ BOURDIEU, Pierre. A economia das trocas linguísticas. São Paulo: Edusp, 1998. p. 81

${ }^{3}$ BATISTA, Nilo. Mídia e sistema penal no capitalismo tardio. Biblioteca Online de Ciências da Comunicação. Disponível em: http://www.bocc.ubi.pt/pag/batista-nilo-midia-sistema-penal.pdf. Acesso em 12.03.2015.

${ }^{4}$ WACQUANT, Loïc. As prisões da miséria. Rio de Janeiro: Zahar, 2011.
} 
verdadeiras cruzadas para legitimar uma intervenção institucional cada vez mais repressiva. ${ }^{5}$

Apesar de não ter capacidade operacional para levar a cabo a política de tolerância zero, por falta de efetivo, esta produziu efeitos colaterais, porque em sua essência apresentou-se da mesma forma que nos países que adotaram essa política, ou seja, a penalização e repressão dos segmentos populares. As práticas policiais com base no ideário "tolerância zero" não significaram uma ampliação da presença policial nos bairros, mas um aumento da intolerância do aparato repressivo-judicial; por consequência, passou a fazer parte da vida cotidiana de moradores de bairros populares e favelas os abusos policiais e as práticas ilegais de repressão.

Não só isso, alinhadas com o estado penal estadunidense, as práticas repressivas provocaram também o avanço do aprisionamento da população pobre do país, pois nos últimos 20 anos a massa carcerária aumentou em $400 \% .{ }^{6}$ Conforme notícias da imprensa nacional, em 2014 o Brasil atingiu um total de 715.655 pessoas encarceradas, passando, assim, a ocupar a terceira posição em números de presos, lugar ocupado anteriormente pela Rússia. ${ }^{7}$

Os fatores que contribuem para inflar a população encerrada atrás das grades são a ampliação generalizada do recurso prisão, o endurecimento das punições e a restrição para se adotar soluções que visem reduzir as penas. Relatório da ONU, por exemplo, aponta que no Brasil as pessoas têm dificuldades de acesso à justiça, há o uso indiscriminado de prisões provisórias e a pena de privação de liberdade está sendo empregada como primeiro recurso em vez de último, como seria exigido pelos padrões internacionais dos direitos humanos. ${ }^{8}$

Esses dados alarmantes de pessoas encarceradas mostram que o endurecimento das penas afasta um contingente cada vez maior da população brasileira da vida social, mas não atinge o objetivo que a respalda, isto é, não diminui os conflitos sociais, muito menos ressocializa os apenados, fator evidenciado pelo déficit de vagas no sistema prisional e pelas constantes

\footnotetext{
${ }^{5}$ BATISTA, op. cit.

${ }^{6}$ http://agenciabrasil.ebc.com.br/geral/noticia/2014-03/populacao-carceraria-aumentou-mais-de-400-nos-ultimos-20-anos-no-brasil. Acesso em 07/10/2014.

${ }^{7}$ No ano de 2014, dados do Conselho Nacional de Justiça (CNJ) mostram que o número de encarcerados chegou a 715.655, fazendo com que o Brasil passasse a ter a terceira população carcerária do mundo, já que ultrapassou a Rússia. http://www1.folha.uol.com.br/cotidiano/2014/06/1465527-brasil-passa-a-russia-e-tem-a-terceira-maior-populacao-carceraria-do-mundo.shtml.

${ }^{8} \mathrm{http}$ ///agenciabrasil.ebc.com.br/direitos-humanos/noticia/2014-09/conselho-de-direitos-humanos-da-onu-debate-situacao-de-prisoes-no-brasil. Acesso em 07/10/2014.
} 
denúncias sobre violação dos direitos humanos e incapacidade do sistema de dar suporte para que o preso, depois de cumprir a pena, possa voltar a viver reintegrado na sociedade.

Aliás, o ambiente carcerário no país tem justamente provocado efeito contrário aos objetivos da lei de execuções penais. A política penal, na realidade, configura-se como forma de punir e vigiar uma população que vive em uma situação marcada pela vulnerabilidade social, característica da sociedade brasileira. O tratamento policial e judicial é desigual e injusto para esse grupo, pois os códigos civil e penal são "aplicados de maneira parcial e incerta", conforme destaca José Murilo de Carvalho, em seu estudo sobre a cidadania no país. ${ }^{9}$

Esses dados mostram que a prisão se configura com o objetivo de isolar a população miserável que incomoda os olhos dessa sociedade "desenvolvida", que um determinado modelo de desenvolvimento econômico, marcado pela concentração de renda, criou. Como a inclusão social aparece como uma quimera, segundo Nilo Batista os novos sistemas penais do empreendimento neoliberal transformaram a finalidade da pena de privação de liberdade e do preceito de ressocialização a uma assumida técnica de neutralização do indivíduo. ${ }^{10}$ Como consequência, o país optou por uma política punitiva que reprime as consequências, tomando medidas de enfrentamento contra essa situação de desordem de forma punitiva, em vez de investir em políticas públicas de promoção da cidadania.

\section{Segurança Pública no Paraná - o avanço do aprisionamento e o gerenciamento dos apenados}

Vários autores que se dedicaram ao estudo das políticas penais e do sistema prisional analisaram diversos aspectos referentes ao seu funcionamento no país. Com a pesquisa que ora realizamos, procuramos avançar nessa temática, mas com um olhar direcionado ao estado do Paraná. Para isso, levantamos dados nas instituições prisionais sobre o número de presos em delegacias e penitenciárias, o regime de cumprimento de penas, grau de instrução, faixa etária, tempo de pena e tipificação do delito dos apenados.

De início, podemos dizer que os dados mostram que o Paraná está entre os seis estados que mais encarceram no país. Nesse sentido, podemos

\footnotetext{
${ }^{9}$ CARVALHO, José Murilo. Cidadania no Brasil: o longo caminho. Rio de Janeiro: Civilização Brasileira, 2011, p. 216

${ }^{10}$ BATISTA, Nilo. Prezada Senhora Viégas: o antrepojeto de reforma no sistema de penas. Discursos Sediciosos, Rio de Janeiro, Relume-Dumará, 2000.
} 
considerar que vem seguindo o movimento de avanço do aprisionamento como forma de lidar com os problemas sociais e, pari passu, contribuindo para colocar o Brasil entre os países que mais encarceram no mundo. ${ }^{11}$ Com essas políticas penais no país é que a taxa de encarceramento passou de 287,31 para 300,96; logo, deparamo-nos com uma superpopulação carcerária. ${ }^{12}$

Em relação ao Paraná, pode parecer que nos últimos anos o estado vinha trilhando um caminho inverso do estado penal, pois entre 2010 e 2012 houve uma diminuição do número de presos. Contudo, devemos salientar que o decréscimo da população carcerária ocorreu em função dos mutirões carcerários realizados pelo Conselho Nacional de Justiça (CNJ) em parceria com a Secretaria de Justiça, Cidadania e Direitos Humanos do Paraná (SEJU). Nessas ações, levadas a cabo conjuntamente pelos governos federal e estadual, foram libertados inúmeros presos que já estavam com o direito de progressão de regime. 0 projeto se iniciou em 2010, sendo realizados 25 mutirões carcerários e expedidos mais de 6.000 alvarás de soltura.

Para termos uma ideia sobre esse movimento de desencarceramento ocorrido no estado, os dados do InfoPen de 2011 mostravam que o Paraná possuía 10.439,601 habitantes e 33.586 pessoas apenadas sob custódia do estado. Isso resultava na constatação de que para cada 100 mil habitantes 321,72 estavam presos. Com os mutirões carcerários, o número de apenados baixou para 31.312, ou seja, 299,93 presos para cada 100 mil habitantes. Apesar dessa diminuição, o estado ainda se encontra entre os seis que mais aprisiona no país; logo, não mudou muito a lógica de usar o aprisionamento como política de segurança pública.

Temos de ressaltar, porém, que se diminuiu o número de encarcerados, isto ocorreu porque muitas pessoas estavam cumprindo penas além do prazo determinado pela lei devido à morosidade dos processos nas instâncias judiciais. Essa situação dos presos é agravada também porque, embora esteja prevista na Constituição de 1988, a Defensoria Pública do estado funciona de uma forma muito precária; logo, não há uma assistência judiciária que possa dar suporte aos aprisionados para, por exemplo, pedir com mais celeridade mudanças no regime de cumprimento de pena. Portanto, no estado do Paraná, citando Zaffaroni, "a sanção penal é a pena e a processual é a nulidade". ${ }^{13}$

\footnotetext{
${ }^{11}$ BOTELHO, Flávia Mestriner (Org. Pesquisa). O sistema penitenciário brasileiro em 2013. Rio de Janeiro: Instituto Avante, janeiro de 2013.

${ }^{12}$ http://www.conectas.org/pt/acoes/justica/noticia/25378-mapa-das-prisoes. Acesso em 10.06.2015

${ }^{13}$ Zaffaroni, Eugenio Raúl. O inimigo no direito penal. Rio de Janeiro: Revan, 2007, p. 111
} 
Vejamos a tabela a seguir para termos uma ideia da quantidade de presos ao longo dos anos analisados.

Tabela 01 - Quantidade de presos no sistema penitenciário e nas delegacias

\begin{tabular}{l|l|l|l|l}
\hline Instituição & 2009 & 2010 & 2011 & 2012 \\
\hline Delegacias & 15.274 & 16.205 & 13.122 & 12.571 \\
\hline Penitenciárias & 22.166 & 19.760 & 20.464 & 20.746 \\
\hline Total & 37.440 & 35.965 & 33.586 & 33.317 \\
\hline
\end{tabular}

Fonte: Sistema Integrado de Informações Penitenciárias (InfoPen).

Nos dados da Tabela 01, podemos verificar que o governo do estado, juntamente com o Conselho Nacional de Justiça e o Ministério Público, utilizou também o mutirão carcerário para diminuir o número de presos nas delegacias e transferi-los para as penitenciárias. Apesar dessa política adotada pelo governo nos últimos anos, boa parte da população prisional do Paraná ainda se encontra em delegacias, local que não é destinado para o cumprimento de pena.

Destacamos também que, devido às condições desses estabelecimentos no estado, que não difere muito do restante do país, eles servem mais como um grande depósito de presos, tendo em vista que são caracterizados pela insalubridade, falta de estrutura para abrigar aprisionados e superlotação. Algumas delegacias possuem até cinco vezes mais presos além da sua capacidade, provocando, com isso, rebeliões e fugas. $O$ relatório de acompanhamento do CNJ (2011) intitulado "Raio X Carcerário" constatou que o Paraná é um lugar de contrastes: existem penitenciárias novas e modernas, mas também inúmeras instituições que atendem apenas à custódia do apenado.

As políticas penais para o sistema prisional no Paraná se mostraram mais focadas na diminuição de apenados em delegacias e sua transferência para as penitenciárias. No entanto, isso apenas muda os problemas de local, porque a estrutura permanece a mesma, já que não há investimentos para que haja aumento do número de vagas. Para exemplificarmos, no ano de 2012 o número de encarcerados no Paraná era de 33.317 presos e havia 20.818 vagas; logo, um déficit de 12.499 vagas, conforme podemos observar na Tabela 02. 
Tabela 02 - Número de vagas no sistema prisional do Paraná

\begin{tabular}{l|r|r|r|r}
\hline Regime & 2009 & 2010 & 2011 & 2012 \\
\hline Fechado & 10.136 & 9.995 & 10.158 & 9.842 \\
\hline Semiaberto & 1.862 & 2.006 & 1.894 & 1.902 \\
\hline Aberto & 0 & 0 & 0 & 0 \\
\hline Provisórios & 2.448 & 2.448 & 2.448 & 2.520 \\
\hline Delegacias & 7.946 & 6.087 & 826 & 6.554 \\
\hline Total & 22.392 & 18.088 & 15.326 & 20.818 \\
\hline
\end{tabular}

Fonte: Sistema Integrado de Informações Penitenciárias (InfoPen).

Os dados apresentados permitem inferir que o número de vagas nas unidades prisionais está muito abaixo do número de pessoas privadas de liberdade. Portanto, a transferência de presos das delegacias para as penitenciárias tem sido realizada sem qualquer planejamento ou observando a capacidade do sistema de absorver os apenados. Como consequência, o estado passou a conviver com inúmeras rebeliões carcerárias nas unidades prisionais de Curitiba e região, as maiores do estado. Devemos destacar que logo que o governo adotou a mesma política de enviar presos para as unidades prisionais fora da capital ou mesmo transferi-los de uma penitenciária a outra, rebeliões começaram a ocorrer em várias cidades do interior do estado. ${ }^{14}$

Nesse sentido que, embora tenha utilizado de modo continuado as transferências, os dados apontam que não há vagas suficientes para comportar os presos que estão sendo enviados para as penitenciárias. 0 problema se agrava também porque há uma insuficiência de profissionais para trabalhar nas unidades penitenciárias no estado, uma vez que o governo vem adotando como política a diminuição do quadro de pessoal nos presídios. Dessa maneira, podemos afirmar que o objetivo do governo é de simplesmente gerir melhor aqueles que cumprem pena nas unidades prisionais do estado.

Diante desse cenário, vale a pena recorrer às palavras de David Garland (2008) para refletirmos sobre o gerenciamento da massa de encarcerados no estado. É bastante claro que para o governo o deslocamento de aprisionados de uma instituição para outra tem como único objetivo minimizar os custos e maximizar a segurança e não devido a uma política que procura respeitar os direitos dos presos ou que vise a sua reinserção e reintegração à sociedade.

\footnotetext{
${ }^{14} \mathrm{http}$ ///www.gazetadopovo.com.br/vida-e-cidadania/em-um-ano-parana-registra-18-revoltas-de-presos-em-presidios-ecjna2m5pkwba4epo5k3lk47i. Acesso em 15/01/2015.
} 
Aqueles que estão sendo transferidos são vistos como sujeitos culpáveis, perigosos, que devem ser cuidadosamente controlados para a proteção do público como "um risco que deve ser administrado". ${ }^{15}$

Para darmos apenas um exemplo, o Conselho Regional do Serviço Social (CRESS) determina que em cada unidade penal um assistente social deve atender até 100 presos; contudo vem atendendo em média 363, o triplo do que é considerado ideal. A falta de profissionais acarreta vários tipos de problemas, potencializando ainda mais as tensões no interior das unidades prisionais, pois os presos não têm suporte educacional, médico ou mesmo jurídico e social.

$\mathrm{Na}$ Tabela 03, podemos ver o quadro de profissionais que trabalham nas unidades prisionais do estado.

Tabela 03 - Quantitativo de Servidores Penitenciários no Paraná

\begin{tabular}{l|l|l|l|l}
\hline Classificação & 2009 & 2010 & 2011 & 2012 \\
\hline Apoio administrativo & 467 & 471 & 444 & 437 \\
\hline Agentes Penitenciários & 3.354 & 3.243 & 3.175 & 3.165 \\
\hline Enfermeiros & 18 & 18 & 18 & 18 \\
\hline Auxiliar Técnico Enfermagem & 109 & 108 & 109 & 108 \\
\hline Psicólogos & 43 & 43 & 39 & 38 \\
\hline Dentistas & 16 & 19 & 20 & 20 \\
\hline Assistentes Sociais & 62 & 62 & 57 & 57 \\
\hline Advogados & 18 & 19 & 16 & 16 \\
\hline Médicos clínicos Gerais & 21 & 22 & 20 & 20 \\
\hline Médicos Psiquiatras & 14 & 13 & 13 & 13 \\
\hline Pedagogos & 10 & 10 & 06 & 06 \\
\hline Terapeutas & 2 & 2 & 2 & 2 \\
\hline Total & 4.134 & 4.030 & 3.919 & 3.900 \\
\hline
\end{tabular}

Fonte: Sistema Integrado de Informações Penitenciárias - InfoPen.

Novamente recorrendo às palavras de David Garland, assinalamos que as políticas penais no estado do Paraná não concebem que a reabilitação do preso seja um objetivo geral, mas simplesmente uma intervenção específica voltada aos indivíduos que reúnam condições de fazer uso mais eficaz de um

${ }^{15}$ GARLAND, David. A cultura do controle: crime e ordem social na sociedade contemporânea. Rio de Janeiro: Editora Revan, 2008. p. 377 
serviço que é visto como oneroso. ${ }^{16}$ Nesse sentido, a reabilitação não é tratada como um direito, mas como um investimento, sendo monitorada e avaliada para assegurar que dê o retorno esperado.

Aliás, se nos países mais desenvolvidos durante boa parte do século XX o previdenciarismo penal tinha como intuito a recuperação e ressocialização do preso, ou seja, havia uma firme convicção de que isso era possível, na sociedade brasileira isto sempre foi feito de uma forma muito residual e marcada por descrédito quanto a sua validade. Na atualidade, o Brasil continua aplicando-a de uma forma muito restritiva, pois qualquer tentativa de ampliá-la é rapidamente desacreditada, porque a lógica é tratar os aprisionados com medidas estritamente penais. Demonstração clara disso são as dificuldades encontradas no estado do Paraná pelos profissionais que trabalham no interior do sistema prisional de realizarem seu trabalho junto aos apenados.

\section{Segurança Pública no Paraná - os alvos preferenciais das políticas penais}

Outro aspecto que analisamos sobre a política de segurança pública no estado do Paraná reporta-se às pessoas que caem nas malhas do sistema prisional paranaense. Tal intento se deve ao fato de que para avançarmos na compreensão de como funcionam as práticas repressivas no Paraná necessariamente temos que desnudar o perfil daqueles que estão sendo aprisionados.

O trabalho aqui é no intuito de desnudar as formas de intervenção do aparato repressivo-judicial no aprisionamento das pessoas no estado. Os dados estatísticos servem para identificar o perfil daqueles que caem nas malhas do sistema prisional do estado, apreender quais são os segmentos sociais alvos preferenciais do aparato repressivo-judicial, bem como a forma de gerenciar a massa de apenados no estado. Com isso, estamos também questionando o pressuposto de que o sistema penal funciona de forma igualitária, que busca prevenir o delito e atinge de forma igual as pessoas em função de suas condutas. ${ }^{17}$

Tal premissa para encaminhamento das reflexões prende-se ao fato de que diversos trabalhos de pesquisa sobre as políticas penais e repressivas no Brasil e também em outros países têm salientado o altíssimo grau de seletividade dirigida aos setores mais vulneráveis. Portanto, o trabalho de reflexão é

\footnotetext{
${ }^{16}$ GARLAND, op. cit., p. 379

${ }^{17}$ BATISTA, Nilo. Os sistemas penais brasileiros. In: ANDRADE, V. R. P. de (Org.). Verso e reverso do controle penal: (des)aprisionando a sociedade da cultura punitiva. Florianópolis: Fundação Boiteux, 2007.
} 
feito no intuito de compreender a seleção criminal levada a cabo pelo aparato repressivo-judicial no estado. Inicialmente, apresentamos uma tabela (Tabela 04) que mostra a escolaridade dos apenados para compreendermos o perfil daqueles que foram alvos preferenciais do aparato repressivo-judicial.

Tabela 04 - Quantidade de presos por grau de instrução

\begin{tabular}{l|l|l|l|l}
\hline Escolaridade & 2009 & 2010 & 2011 & 2012 \\
\hline Analfabeto & 1.232 & 808 & 752 & 720 \\
\hline Alfabetizado & 1.569 & 1.045 & 1.338 & 1.312 \\
\hline Fundamental Incompleto & 10.592 & 10.437 & 10.144 & 11.054 \\
\hline Fundamental Completo & 2.756 & 2.378 & 2.479 & 2.153 \\
\hline Médio Incompleto & 3.247 & 2.650 & 3.174 & 2.919 \\
\hline Médio Completo & 2.254 & 1.893 & 2.019 & 2.033 \\
\hline Superior Incompleto & 237 & 286 & 377 & 369 \\
\hline Superior Completo & 270 & 230 & 157 & 159 \\
\hline Acima Superior Completo & 09 & 24 & 28 & 27 \\
\hline Total & 22.166 & 19.760 & 20.468 & 20.746 \\
\hline
\end{tabular}

Fonte: Sistema Integrado de Informações Penitenciárias (InfoPen).

Ao observarmos a Tabela 04, identificamos que a grande maioria dos apenados não concluiu o ensino fundamental, e somados àqueles com fundamental completo, constituem mais de $50 \%$ da população aprisionada. Vale destacar que os números se mantêm quase que em uma constante ao longo dos anos pesquisados. Portanto, o aprisionamento dessas pessoas não se deve a situações momentâneas que possam ter levado a uma desestabilização da vida social, mas precisamente porque têm maiores chances de serem etiquetadas como delinquentes ou criminosos, logo, passíveis de serem detidas ou aprisionadas.

A Tabela 04 se mostra decrescente conforme cresce a escolaridade, demonstrando como aqueles que possuem maior instrução ficam quase ilesos das ações do aparato repressivo-judicial. Essas diferenças demonstram que parte da sociedade fica blindada, pois, enquanto os indivíduos de baixa renda pagam a pena com sua própria liberdade, aqueles com poder aquisitivo contam com "uma série infindável de imunidades que torna mais difícil a aplicação universal das leis penais". ${ }^{18}$

${ }^{18}$ ADORNO, Sérgio. Crime, justiça penal e desigualdade jurídica. Revista USP, São Paulo, n. 21, p. 132-151, mar./abr. 1994, p. 149 
Essa desigualdade pode ser explicada também pelo fato de que as pessoas com maior escolaridade possuem maior capacidade jurídica para entender como o sistema repressivo-judicial funciona; por conseguinte, sabem melhor garantir seus direitos, defender-se das arbitrariedades do estado. Mesmo porque, como diz Zaffaroni, não escrevam obituários ao estado de polícia, porque ele está bem vivo dentro de todo estado de direito, ele nunca cessa de pulsar. ${ }^{19}$ Além disso, as pessoas com maior poder aquisitivo podem contar com boa assistência advocatícia para fazer frente aos processos judiciais. Por outro lado, as pessoas com baixa escolaridade são mais vulneráveis, pois encontram muitos problemas jurídicos como grupo ou classe, tendo em vista que não compreendem muito bem seus direitos ou mesmo como identificar como podem se valer de remédios jurídicos para se defender das ações do aparato estatal, principalmente em relação à alta seletividade do poder punitivo. ${ }^{20}$

Os dados relativos à escolaridade são importantes também para comprovar que a universalidade ou impessoalidade das ações do aparato repressivo-judicial, como apregoa o discurso oficial, não condiz com a realidade, porque a população carcerária é uma demonstração clara da "objetivação das diferenças e das desigualdades, a manutenção das assimetrias, a preservação das distâncias e das hierarquias", conforme palavras de Sérgio Adorno ${ }^{21}$ Isto porque os dados educacionais dos apenados permitem identificar a classe social, uma vez que na sociedade brasileira o grau de escolaridade tem uma relação direta com o nível econômico.

$\mathrm{Na}$ Tabela 05, podemos perceber que grande parte dos apenados encontra-se na média de idade entre 18 e 29 anos, o que corresponde a mais de $50 \%$ dos pesquisados. Portanto, os dados do InfoPen demonstram que o perfil da população carcerária paranaense é majoritariamente composta por pessoas muito jovens. Como na questão da escolaridade, novamente notamos que os números se mantêm quase que em uma constante nos anos pesquisados.

\footnotetext{
${ }^{19}$ ZAFARRONI, Eugenio Raúl. O inimigo no direito penal. Rio de Janeiro: Revan, 2007. p. 170

${ }^{20}$ CAPPELLETTI, Mauro e GARTH, Bryant. Acesso à justiça. Porto Alegre: Sérgio Antonio Fabris Editor, 2002. p. 38

${ }^{21}$ ADORNO, op cit., p. 149
} 
Políticas penais no Paraná - do avanço do aprisionamento ao gerenciamento da massa de ...

Tabela 05 - Quantidade de presos por faixa etária

\begin{tabular}{l|l|l|l|l}
\hline Faixa etária & 2009 & 2010 & 2011 & 2012 \\
\hline 18 a 24 anos & 6.345 & 5.242 & 5.247 & 5.343 \\
\hline 25 a 29 anos & 5.869 & 5.198 & 5.361 & 5.375 \\
\hline 30 a 34 anos & 4.129 & 3.618 & 3.891 & 3.892 \\
\hline 35 a 45 anos & 3.681 & 3.756 & 3.878 & 3.972 \\
\hline 46 a 60 anos & 1.878 & 1.682 & 1.797 & 1.860 \\
\hline Mais de 60 anos & 259 & 264 & 290 & 304 \\
\hline Total & 22.161 & 19.760 & 20.464 & 20.746 \\
\hline
\end{tabular}

Fonte: Sistema Integrado de Informações Penitenciárias (InfoPen).

Os resultados demonstram que o estado tem uma situação muito similar ao restante do país, qual seja, pessoas pertencentes a uma determinada classe social logo que iniciam a sua vida adulta têm grandes possibilidades de serem etiquetadas de criminosas; por conseguinte, mais sujeitas às ações do aparato repressivo judicial. Isso deixa evidente a seletividade presente nas ações do aparato repressivo judicial, que leva uma população marginalizada a ser a "clientela" preferencial do sistema penal. Não são alvos enquanto indivíduos determinados, mas porque pertencem a uma categoria de sujeitos de risco. ${ }^{22}$ Nesse sentido, citamos as palavras de Vera Andrade de que a descoberta de um código social extralegal passou de uma explicação da regularidade da etiologia da tendência a delinquir para outra que identifica as maiores "oportunidades" de ser criminalizado. ${ }^{23}$ Eugenio Raul Zaffaroni chega a fazer menção sobre a existência de um sistema penal paralelo nos países da América Latina. ${ }^{24}$

Outro aspecto que não podemos abandonar na análise sobre as políticas penais no estado do Paraná refere-se à quantidade de tempo imposta como punição aos aprisionados, considerando que isto pode revelar aspectos importantes sobre como ocorre o processo da seleção criminal no estado. Salta aos olhos nos dados estatísticos que grande parte da população que cumpre pena em unidades prisionais não cometeu atos qualificados como violentos e de alto poder ofensivo, pois a maioria das condenações não ultrapassa 04

\footnotetext{
${ }^{22}$ DE GIORGI, Alessandro. Tolerancia cero: estrategias y prácticas de la sociedad de control. Barcelona: Virus editorial, 2005, p. 93

${ }^{23}$ ANDRADE, Vera Regina Pereira. Sistema penal máximo x cidadania mínima: códigos de violência na era da globalização. Porto Alegre: Livraria do Advogado, 1997, p. 270

${ }^{24}$ ZAFFARONI, op.cit.
} 
anos e é cumprida, como afirmamos anteriormente, em sua grande maioria por pessoas muito jovens.

Quando nos deparamos com os dados constantes da Tabela 06 (a seguir), fica claro que a política repressiva no Paraná segue as premissas do ideário do estado penal, pois tem optado por privar de liberdade aquelas pessoas que cometem atos qualificados de baixa gravidade apenas por atenderem ao estereótipo do criminoso formado pelo imaginário social. Como ressalta Wacquant, é "insensato pretender tratar os ilícitos menores como um instrumento tão grosseiro e ineficaz como é a prisão" sem qualquer reflexão por parte das autoridades sobre os efeitos "perversos e os danos sociais causados pela intensificação indiscriminada da repressão penal e pela extensão incontrolada de um aparelho prisional já sobrecarregado". ${ }^{25}$

Podemos considerar ainda que manter na prisão uma população que cumpre pena de até 04 anos nada mais faz do que resvalar em uma escalada penal sem fim e sem saída, para recorrermos as reflexões de Wacquant, sem fazer uma discussão mais profunda sobre as ações qualificadas como delinqüência e sua relação com as questões que geram esse cenário de conflituosidades e insegurança social entre aqueles segmentos mais vulneráveis da população.

Tabela 06 - Quantidade de presos por tempo total das penas

\begin{tabular}{l|l|l|l|l}
\hline Penas & $\mathbf{2 0 0 9}$ & $\mathbf{2 0 1 0}$ & $\mathbf{2 0 1 1}$ & $\mathbf{2 0 1 2}$ \\
\hline Até 04 anos & 9.748 & 5.787 & 6.604 & 6.280 \\
\hline Mais de 04 até 08 anos & 4.008 & 5.042 & 5.291 & 5.315 \\
\hline Mais de 08 até 15 anos & 2.553 & 3.201 & 3.322 & 3.420 \\
\hline Mais de 15 até 20 anos & 1.227 & 1.232 & 1.423 & 1.524 \\
\hline Mais de 20 até 30 anos & 1.087 & 996 & 1.064 & 1.164 \\
\hline Mais de 30 até 50 anos & 299 & 329 & 418 & 419 \\
\hline Mais de 50 até 100 anos & 47 & 48 & 54 & 54 \\
\hline Mais de 100 anos & 03 & 08 & 07 & 07 \\
\hline Total & $\mathbf{1 8 . 7 9 2}$ & $\mathbf{1 9 . 7 6 0}$ & $\mathbf{1 8 . 1 8 3}$ & $\mathbf{1 8 . 1 8 3}$ \\
\hline
\end{tabular}

Fonte: Sistema Integrado de Informações Penitenciárias (InfoPen).

Os dados da Tabela 07 revelam que a grande maioria da população prisional está detida por algum crime contra o patrimônio, ou seja, roubo ou

${ }^{25}$ WACQUANT, Loïc. As duas faces do gueto. São Paulo: Boitempo, 2004, p. 223 
furto. É importante destacar que os delitos patrimoniais, os quais levam um maior contingente de pessoas para a prisão, são, em sua maioria, os que não apresentam violência, como o furto e o roubo. Isso desmonta a visão que se tem de que as prisões estão cheias de pessoas consideradas de alta "periculosidade", como o latrocínio (roubo seguido de morte) ou sequestro etc.

Tabela 07 - Quantidade de crimes tentados - consumados

\begin{tabular}{l|l|l|l|l}
\hline Crimes & $\mathbf{2 0 0 9}$ & $\mathbf{2 0 1 0}$ & $\mathbf{2 0 1 1}$ & $\mathbf{2 0 1 2}$ \\
\hline Contra a pessoa & 3.122 & 2.690 & 2.071 & 2.326 \\
\hline Contra o patrimônio & 14.135 & 14.387 & 10.119 & 10.657 \\
\hline Contra os costumes & 1.206 & 1.147 & 1.047 & 1.124 \\
\hline Contra a paz pública & 290 & 321 & 272 & 247 \\
\hline Contra a fé pública & 186 & 229 & 168 & 175 \\
\hline Contra a Adm. Pública & 77 & 101 & 87 & 26 \\
\hline Entorpecentes & 972 & 4.784 & 4.750 & 5.124 \\
\hline Estat. do desarmamento & 1.480 & 1.105 & 1.007 & 1.124 \\
\hline Total & $\mathbf{2 4 . 4 8 0}$ & $\mathbf{1 9 . 7 6 0}$ & $\mathbf{2 0 . 4 9 4}$ & $\mathbf{2 0 . 8 0 8}$ \\
\hline
\end{tabular}

Fonte: Sistema Integrado de Informações Penitenciárias (InfoPen).

Não podemos deixar de ressaltar também que tem-se utilizado o sistema penal para responder a todos os tipos de atos lesivos presentes na sociedade, conforme os dados da Tabela 07. Pessoas presas, por exemplo, por envolvimento com comércio ilegal de drogas representa $1 \frac{1}{4}$ da população prisional. Nesse caso, especialistas vêm apontando que resolver o problema das drogas somente com direito penal tem se mostrado ineficaz, além de aumentar o nível de violência, tanto do aparato repressivo judicial para lidar com a população envolvida com o comércio ilegal de drogas, como dos agentes envolvidos com esse tipo de atividade, já que esta ocorre sem a presença de qualquer tipo de controle por parte dos órgãos públicos.

Podemos também incluir nesse rol se é, de fato, por intermédio do aparato repressivo judicial que o estado deve responder a todos os atos lesivos que vão se avolumando na sociedade, tais como crimes contra os costumes, contra a paz pública, contra a administração pública ou contra o estatuto do desarmamento. A impressão é de que, seguindo as palavras de Zaffaroni, quando não se sabe o que fazer com um conflito social atribui-se a responsabilidade ao direito penal. ${ }^{26}$

${ }^{26}$ ZAFFARONI, op. cit. 


\section{Considerações finais}

Como considerações finais, podemos destacar que o ideário penal estadunidense foi recepcionado no Brasil com grande entusiasmo justamente quando iniciávamos uma nova experiência democrática, depois de anos de ditadura militar. Os reflexos dessa ação se deram no sentido de conceber que os grandes problemas sociais no país deveriam ser tratados como uma questão criminal. Como resultado, tivemos o avanço significativo do aprisionamento, levando o país a ocupar a terceira posição mundial em número de encarcerados.

Portanto, se pensávamos em um rompimento mais significativo na relação do estado com os segmentos sociais mais vulneráveis da população com o fim da ditadura, a realidade é justamente outra, porque o autoritarismo se manteve quase intacto, podendo ser percebido nas ações repressivas da polícia em bairros ocupados por segmentos populares ou favelas. A política de "tolerância zero" que apareceu como o canto da sereia para a imprensa e uma parcela da população acabou aumentando a intolerância do aparato policial em relação aos segmentos sociais populares.

Tratando especificamente da população prisional paranaense, podemos assinalar que possui um histórico de vida muito similar: é majoritariamente jovem, sem o ensino fundamental completo, com dificuldades de inserção no mercado de trabalho devido ao seu baixo nível de escolarização, sem qualificação profissional, usuários de substâncias psicoativas em sua maioria e, quando em liberdade, passam a exercer subempregos no mercado informal de trabalho.

Os dados coletados apontaram a seletividade criminal, já que o perfil social daqueles que cumprem prisão é muito parecido, uma vez que 50\% dos apenados se encontram entre aqueles que terminaram o ensino fundamental ou sequer concluíram essa etapa de estudo. E quando identificamos que os dados são uma constante ao longo dos anos pesquisados, esse fato revela que o aprisionamento dessas pessoas não se deve a situações momentâneas que pudessem ter levado a uma desestabilização da vida social, mas precisamente porque têm maiores chances de serem etiquetadas de criminosas, logo, passíveis de serem detidas ou aprisionadas.

Para finalizar, identificamos também que o perfil da população carcerária paranaense é majoritariamente de pessoas muito jovens. Portanto, se nos basearmos nos dados sociais e econômicos, mais a faixa etária, vamos claramente perceber que as pessoas pertencentes a uma determinada classe social logo que iniciam a sua vida adulta têm grandes possibilidades de serem 
Políticas penais no Paraná - do avanço do aprisionamento ao gerenciamento da massa de ...

alvos das instituições de controle estatal. Portanto, esse sistema penal paralelo existente faz com que possamos identificar maiores "oportunidades" de uma pessoa, pertencente a um determinado segmento social, ser criminalizada.

Artigo recebido para publicação em 16/12/2015

Artigo aprovado para publicação em 01/04/2016 